\title{
Pattern of Pain and Swelling after Periapical and Wisdom Tooth Surgery: Are age and Gender Predictive Factors?
}

\author{
Abdurrahman Ali Al-Samman
}

B.D.S., M.Sc. (Oral and Maxillofacial surgery)

Department of oral surgery, Tikrit specialized dental center, Salahiddin health directorate, Ministry of health, Iraq.

\begin{abstract}
Objectives: The aim of this study is to evaluate the intensity of post-surgical pain and swelling experienced by patients who had undergone lower third molar and periapical surgery $\{(\mathrm{L} 3 \mathrm{MS}),(\mathrm{PAS})\}$, and also to investigate the impact of age and gender on the same parameters. .

Methods: The study involved 86 patients; some of whom underwent L3MS $(n=46)$, while the others had PAS ( $n=40)$, all procedures were performed under local anesthesia. The visual analogue scale measured pain and swelling for seven consecutive days, after surgery.

Results: After L3MS, it was found that patients experienced the most intense pain the day of surgery, with facial swelling reaching a maximum on the 2 nd day. In addition, the influence of age and gender on the intensity of pain and degree of swelling was found to be insignificant...

Patients who underwent PAS; also reported maximum pain on the day of surgery while swelling reached maximum on the 2 nd day. However, female patients reported significantly more post-operative pain than males $(P<0.024)$. No significant differences between females and males were recorded with respect to post-operative swelling, in addition, age was found to have no effect on both pain and swelling.

Conclusion: Pain and swelling after L3MS and PAS peaked on the day of surgery and the day after respectively with mild to moderate intensity, it subsided gradually to minimal levels on day 7. Short-term outcomes of L3MS and PAS with respect to degrees of pain and swelling were found to be similar, and it seems to be independent of both' age and gender.
\end{abstract}

KEY WORDS

Pain, Swelling, Periapical surgery, Wisdom tooth surgery

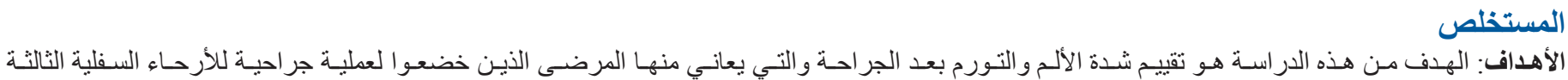

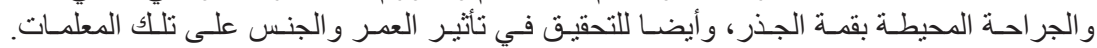

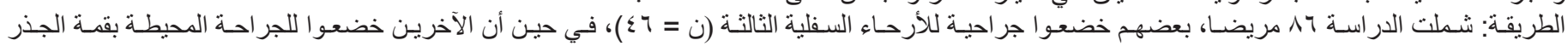

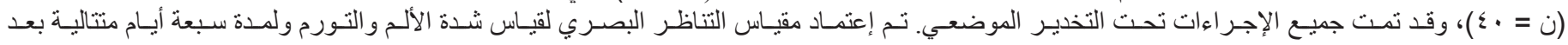

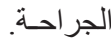

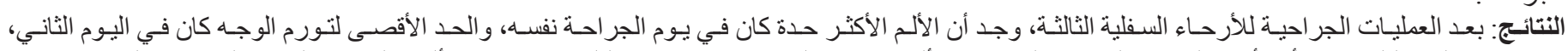

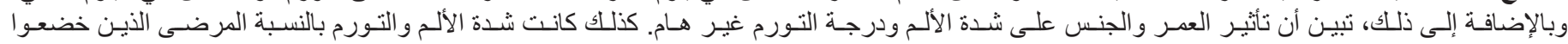

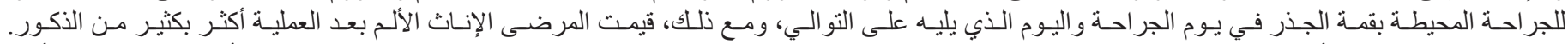

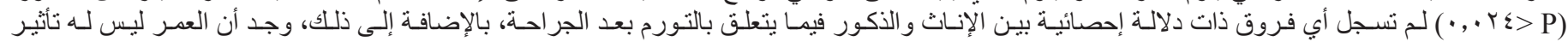

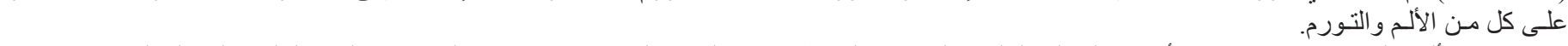

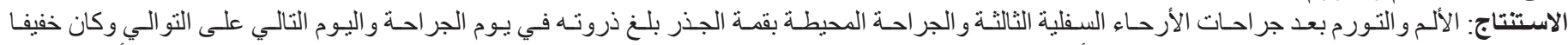

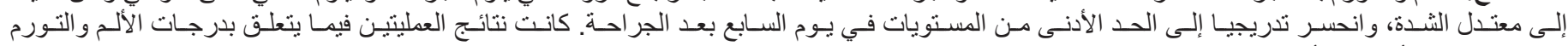

\section{INTRODUCTION}

Surgical operations are common procedures in dental practice. They can be uncomfortable for patients due to post-operative complications (1). Pain and swelling are amongst those undesirable consequences of surgery and are a major concern for most patients (2). Dentists should be able to provide information on the anticipated degree of discomfort after surgery (3), and should have in mind the strategies to limit and deal with such issues should they arise.

Surgical removal of impacted lower third molars (L3M) is one of the most frequently performed procedures in oral and maxillofacial surgical practice (4). Periapical surgery (PAS) is indicated when conservative root canal treatments fail to retain teeth that have persistent periradicular pathosis. Both of the above procedures involve trauma to the soft and hard tissues leading to an inflammatory response and various subsequent post-operative complications like pain and swelling.

There are many published articles reporting the severity of pain and swelling occurring after lower third molar surgery (L3MS) ${ }^{(2,5-12)}$ and PAS (13-20). Studies have found that after L3MS, maximum pain intensity is within 6 hours of the operation ${ }^{(5,7,21)}$ or on the day after surgery ${ }^{(8,11)}$. While as far as swelling is concerned, researchers found it to be maximum on the second ${ }^{(8-10)}$ or third post-operative day ${ }^{(5,11,21)}$. The impact of patients' age and gender on immediate postoperative complications is somewhat conflicting. About L3MS, some researchers reported no effect of age ${ }^{(22-25)}$ or gender ${ }^{(22,26)}$ on such complications. While on the contrary, others found that age ${ }^{(25,27-29)}$ and gender ${ }^{(25,27,30,31)}$ are key factors in predicting the 
degree of post-operative discomfort in patients.

Similar findings were reported regarding PAS; it was found that; maximum pain intensity was in the immediate postoperative period, Some Studies recorded maximum pain in the 2-5 hours after surgery ${ }^{(3,16,32)}$; or on the same day and night of the operation $(13,18,19)$. Other studies found that maximum pain intensity occurs on the first ${ }^{(14,15,33,34)}$, or second day after the operation ${ }^{(17,20)}$. Swelling was observed in all patients and reach a maximum on the first $(3,13,19)$ or second ${ }^{(15,32,17)}$ post-operative day. Many studies found no relationship between post-operative discomfort and age ${ }^{(14,15,17,18,20)}$ or gender ${ }^{(14-18,20)}$. However, other researchers found more pain and swelling in young female patients ${ }^{(19)}$.

The aim of the current study is to evaluate the intensity of pain and swelling after L3MS and PAS throughout the immediate post-operative period, and to investigate the impact of patients' age and gender on such complications.

\section{Patients and methods:}

Study design and Sample: The study was approved by the ethics committee of the Ministry of Health in IRAQ and was conducted at the Department of the Oral Surgery/The Left Specialized Dental Center, Mosul City.

Inclusion criteria: The participants were healthy individuals with no systemic diseases (American Society of Anesthesiologists grade I) who needed L3MS or PAS including flap reflection and bone removal.

Exclusion criteria: Medically compromised patients including, female patients who were pregnant or on oral contraceptives, aged below 18 years, Pell and Gregorys' class III and/or level C L3M impaction, multiple and/or posterior teeth with periapical lesion, cognitive or mental disability, and patients who refuse to participate.

Eighty-six patients were selected for the study, all of whom expressed an interest to participate and provided written informed consent. The Patients were subdivided into two groups: Group 1 consist of 46 patients (underwent L3MS); group 2 consist of 40 patients (underwent PAS).

Surgical Procedure: Three specialists performed the surgical procedures under local anesthesia using $2 \%$ lidocaine with 1:100,000 epinephrine. For L3MS, a full-thickness triangular flap was reflected to gain access to the third molar. Osteotomy was performed with the bur under constant irrigation, and tooth sectioning was done when necessary. The flap was repositioned and sutured hermetically by $3 / 0$ silk sutures. In PAS, triangular full mucoperiosteal flap was reflected, osteotomy and perpendicular root-end resection using a high-speed bur, curettage, trimming of surface irregularities were completed under constant irrigation. The flap was re-approximated and sutured by $3 / 0$ silk sutures. Postoperatively, for both groups, amoxicillin $500 \mathrm{mg}$ and ibuprofen $200 \mathrm{mg} 3$ times daily for 5 days were prescribed to all patients. In addition, post-operative instructions were given verbally by the operators as well as in written form.

After surgery, the patients were asked to record the severity of their pain on a plain horizontal visual analog scale (VAS), which consists of a horizontal line $100 \mathrm{~mm}$ in length, with the ends 'No pain' and 'Worst imaginable pain' placed at each end of the line. Using another VAS, patients recorded swelling in the same way, with the ends 'No swelling' and 'Worst imaginable swelling. Patients were asked to make a mark on the VAS that best represents the intensity of their pain and to rate their swelling on the other VAS daily beginning on the night of the day of surgery and for 6 consecutive days . Pain and swelling scores were compiled from patients when they attended for suture removal and for examination of the surgical wound after seven days.

Paired-Samples $\mathrm{T}$ Test, independent sample $\mathrm{T}$ test, and Chi-square test were used in the data analysis (IBM SPSS Statistic 23, SPSS Inc., Chicago, IL, USA).

\section{RESULTS}

The distribution of patients with respect to the surgical intervention, age grouping and gender is shown in table (1).

Table (1):L3MS and PAS: Number of patients concerning their age and gender.

\begin{tabular}{c}
$\begin{array}{c}\text { Surgical inter- } \\
\text { vention }\end{array}$ \\
\hline L3MS \\
PAS
\end{tabular}

\begin{tabular}{c}
$\begin{array}{c}\text { Number of } \\
\text { patients }\end{array}$ \\
\hline 40 \\
36
\end{tabular}

\begin{tabular}{|c|c|c|}
\hline \multicolumn{3}{|c|}{ Age group } \\
\hline$<\mathbf{2 6}$ & $\geq 26$ & Sig. \\
\hline 20 & 20 & 1.00 \\
\hline 16 & 20 & 0.505 \\
\hline
\end{tabular}

\begin{tabular}{|c|c|c|}
\hline \multicolumn{3}{|c|}{ Gender } \\
\hline Male & Female & Sig. \\
\hline 22 & 18 & 0.527 \\
\hline 12 & 24 & $0.046^{*}$ \\
\hline
\end{tabular}

$\mathrm{SD}=$ Standard deviation.

*Significant at the 0.05 level (Chi-square test).

L3MS group: Of the forty-six patients who patients returned. Three patients (6.98\%) were expressed an interest to participate, forty-three excluded; one did not know how to use VAS and two 
did not complete their rating of pain and/or swelling for 7 days. The included patients were twenty-two males $(55 \%)$ and eighteen females $(45 \%)$.

By pooling all patients, the pain mean value reached a maximum at the night of the day of surgery (day 1); it was moderate and subsided gradually to almost no pain on day 6 (Table 2, Fig. 1), Four patients $(10 \%)$ out of the sample reported no pain (Table 3 ). There was a statistically significant difference between the VAS score for pain in day 1 compared with day 2,3 , and $4(P<0.028$, paired $t$-test $)$. Facial swelling was recorded by most of patients $(92.5 \%)$ and the mean of VAS scores reached a maximum on the first postoperative day (Table 2), there was a statistically significant difference with the following postoperative days $(P<0.018$, paired $t$-test). The swelling was mild and subsided gradually, where about $70 \%$ of patients had no swelling on the sixth post-operative day (Table 2, Fig.1). Although female patients reported more postoperative pain and swelling than males, there were no significant differences between the two groups (Table 4, Fig.2). Similarly, no significant difference was reported between young and old patients with respect to postoperative pain and swelling (Table 4, Fig.3).

Table (2):L3MS and PAS: Postoperative pain and swelling mean values (VAS).

\begin{tabular}{|l|c|c|c|c|c|c|c|c|}
\hline & \multicolumn{2}{|c|}{ L3MS-Pain } & \multicolumn{2}{c|}{ L3MS -Swelling } & \multicolumn{2}{c|}{ PAS-Pain } & \multicolumn{2}{c|}{ PAS-Swelling } \\
\cline { 2 - 11 } & Mean & SD & Mean & SD & Mean & SD & Mean & SD \\
\hline Day1 & 49.2 & 29.2 & 26.2 & 22.1 & 37.6 & 31.2 & 45.6 & 27.2 \\
\hline Day2 & 32.4 & 24.4 & 32.6 & 23.4 & 25.4 & 31.6 & 51.6 & 20.8 \\
\hline Day3 & 29.7 & 28 & 31.1 & 22.3 & 18.4 & 25.3 & 41.3 & 21.2 \\
\hline Day4 & 15.9 & 18.2 & 20.9 & 16 & 16.2 & 25.4 & 30.7 & 21.5 \\
\hline Day5 & 11.8 & 16.1 & 13.3 & 16.3 & 12.2 & 23.7 & 19.4 & 24.3 \\
\hline Day6 & 4.3 & 11.3 & 10.2 & 13.9 & 12.8 & 24 & 12.3 & 21.1 \\
\hline Day7 & 4.5 & 13.4 & 4 & 12.5 & 4.7 & 12.8 & 7 & 11.1 \\
\hline
\end{tabular}

$\mathrm{SD}=$ Standard deviation.

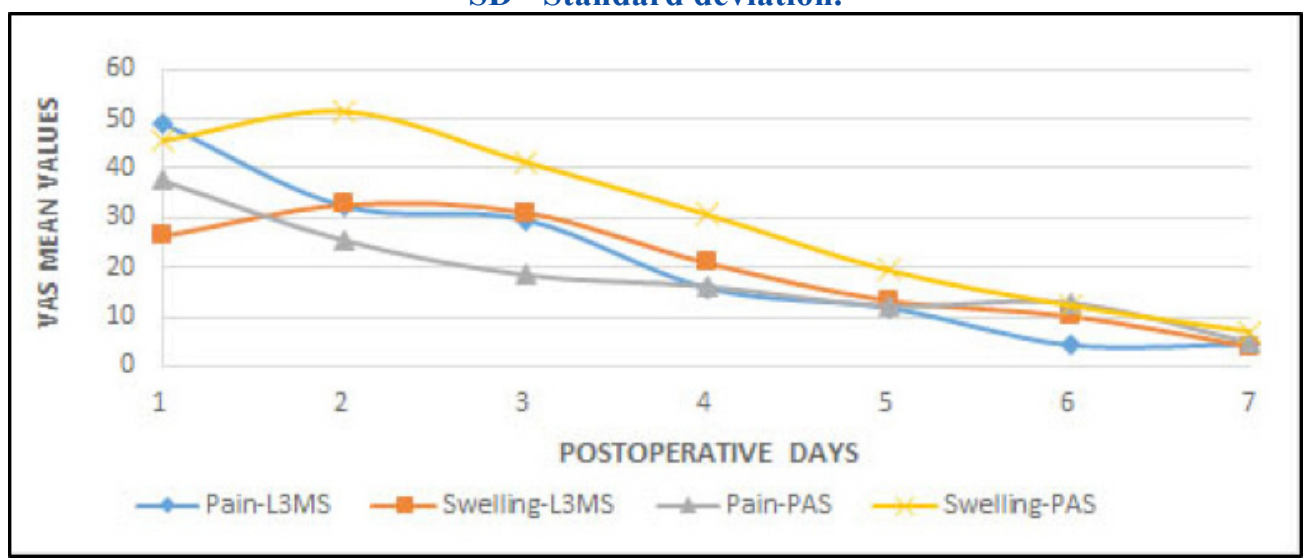

Fig.1: Postoperative pain and swelling values after L3MS and PAS

Table (3): L3MS: Percent (\%) of patients having postoperative pain and swelling.

\begin{tabular}{|c|c|c|c|c|c|c|c|}
\hline $\begin{array}{c}\text { Rating of postoperative } \\
\text { complain }\end{array}$ & Day1 & Day2 & Day3 & Day4 & Day5 & Day6 & Day7 \\
\hline No pain & 5 & 7.5 & 35 & 50 & 57.5 & 77.5 & 77.5 \\
\hline Mild pain & 10 & 62.5 & 35 & 47.5 & 40 & 20 & 20 \\
\hline Moderate pain & 65 & 30 & 27.5 & 0 & 2.5 & 2.5 & 0 \\
\hline Severe pain & 20 & 0 & 2.5 & 2.5 & 0 & 0 & 2.5 \\
\hline No swelling & 12.5 & 7.5 & 7.5 & 7.5 & 42.5 & 57.5 & 70 \\
\hline Mild swelling & 57.5 & 62.5 & 60 & 90 & 55 & 40 & 27.5 \\
\hline Moderate swelling & 30 & 30 & 30 & 0 & 2.5 & 2.5 & 0 \\
\hline Severe swelling & 0 & 0 & 2.5 & 2.5 & 0 & 0 & 2.5 \\
\hline
\end{tabular}


Table (4):L3MS and PAS: Statistical significance* in age and gender concerning postoperative pain and swelling.
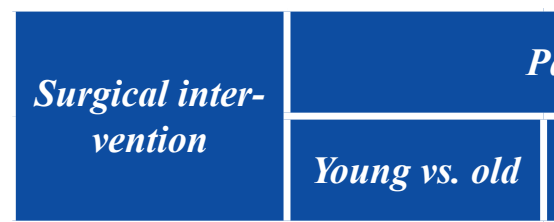

\section{Pain}

L3MS

PAS

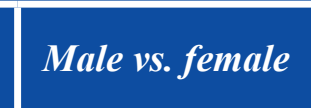

0.673

0.159

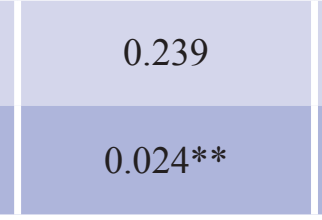

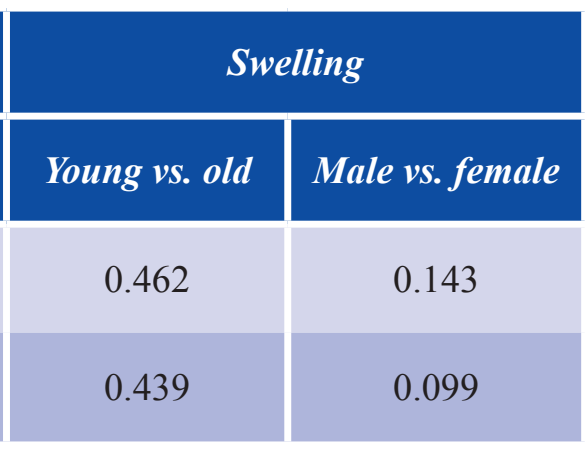

* Independent sample T test

$* *$ Significant at the 0.05 level (2-tailed).

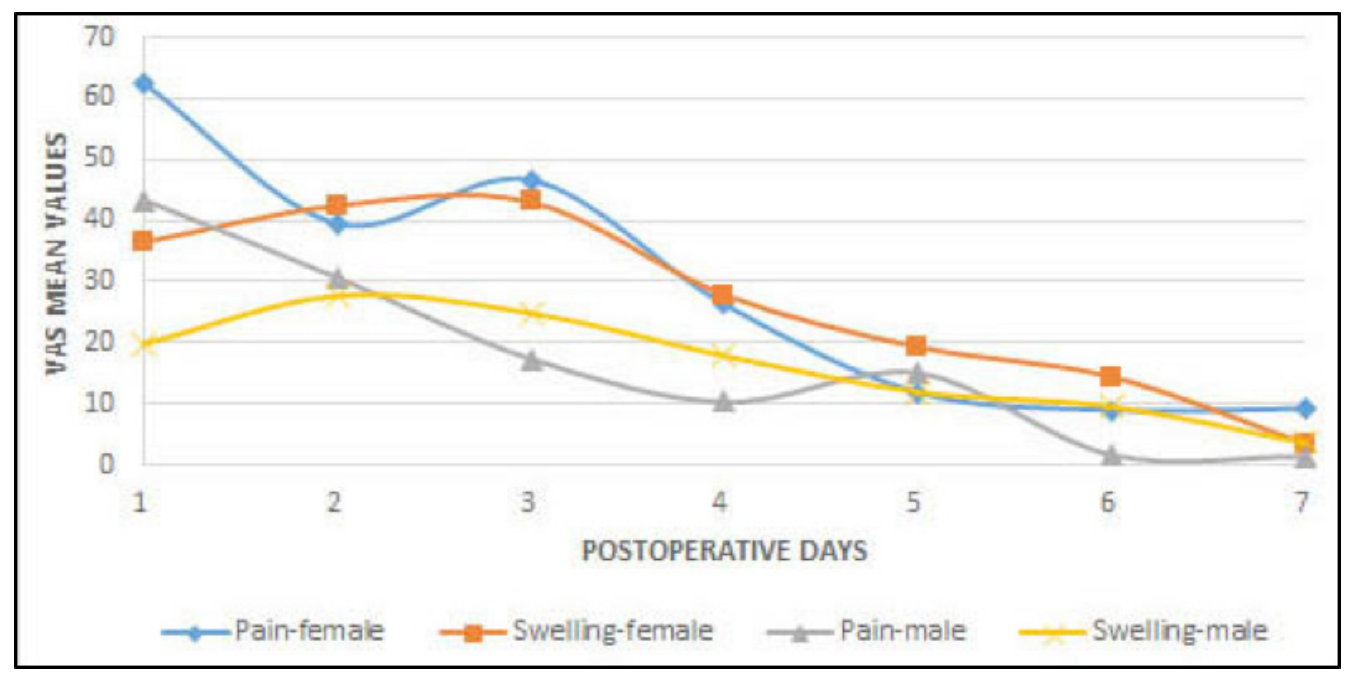

Fig.2: Gender-related postoperative pain and swelling values after L3MS

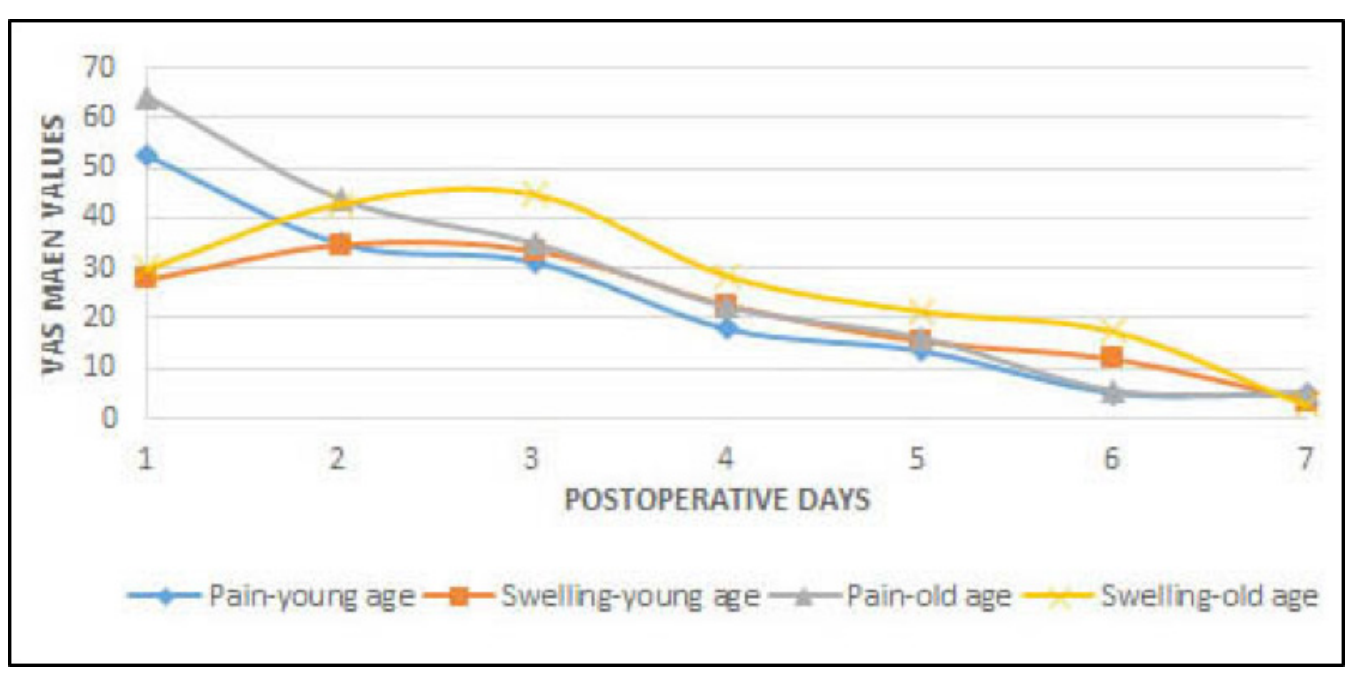

Fig.3: Age-related postoperative pain and swelling values after L3MS

PAS group: All forty patients who participated in maximum on the night of the day of surgery (day 1); it the study returned for suture removal. Four patients $(10 \%)$ were excluded as they did not rate their pain and/or swelling for the whole period of study. The remaining patients were; twelve males $(33.3 \%)$ and twenty-four females $(66.7 \%)$. was mild and subsided gradually to almost no pain on day 7 (Table 2, Fig.1). However, four patients (11.1\%) reported no pain on day 1 (Table 5). There was a statistically significant difference between the VAS

The mean of VAS score for pain reached a score recorded on day 1 compared to the following 4 post-operative days $(P<0.021$, paired $t$-test $)$. 
Table (5): PAS: Percent (\%) of patients having postoperative pain and swelling.

\begin{tabular}{|r|r|r|r|r|r|r|r|}
\hline $\begin{array}{r}\text { Rating of postoperative } \\
\text { complain }\end{array}$ & \multicolumn{1}{l|}{ Day1 } & Day2 & Day3 & Day4 & Day5 & Day6 & Day7 \\
\hline No pain & 11.1 & 44.4 & 50 & 44.4 & 55.5 & 61 & 83.3 \\
\hline Mild pain & 47.2 & 38.9 & 38.9 & 44.4 & 38.9 & 27.8 & 11.1 \\
\hline Moderate pain & 25 & 0 & 0 & 5.6 & 0 & 5.6 & 5.6 \\
\hline Severe pain & 16.7 & 16.7 & 11.1 & 5.6 & 5.6 & 5.6 & 0 \\
\hline No swelling & 11.1 & $0 \%$ & 11.1 & 16.7 & 33.3 & 66.6 & 66.7 \\
\hline Mild swelling & 44.4 & $38.8 \%$ & 33.3 & 61 & 61.1 & 27.8 & 33.3 \\
\hline Soderate swelling & 27.8 & $55.6 \%$ & 55.6 & 16.7 & 0 & 0 & 0 \\
\hline
\end{tabular}

With respect to post-operative swelling, this was reported by $88.9 \%$ of patients on day 1 and reached a maximum on the first post-operative day (Table 2, Fig.1). There was a statistically significant difference with the following post-operative days ( $P<$ 0.013 , paired $t$-test). The swelling was moderate and subsided gradually, where about two thirds of patients had no swelling on the fifth post-operative day (Table

5). Females reported more post-operative pain than male patients did; with a significant difference between them. However, there was no significant difference between the genders in terms of postoperative swelling (Table 4, Fig.4). In addition, no significant difference was recorded between young and old patients with respect to post-operative pain and swelling (Table 4, Fig.5).

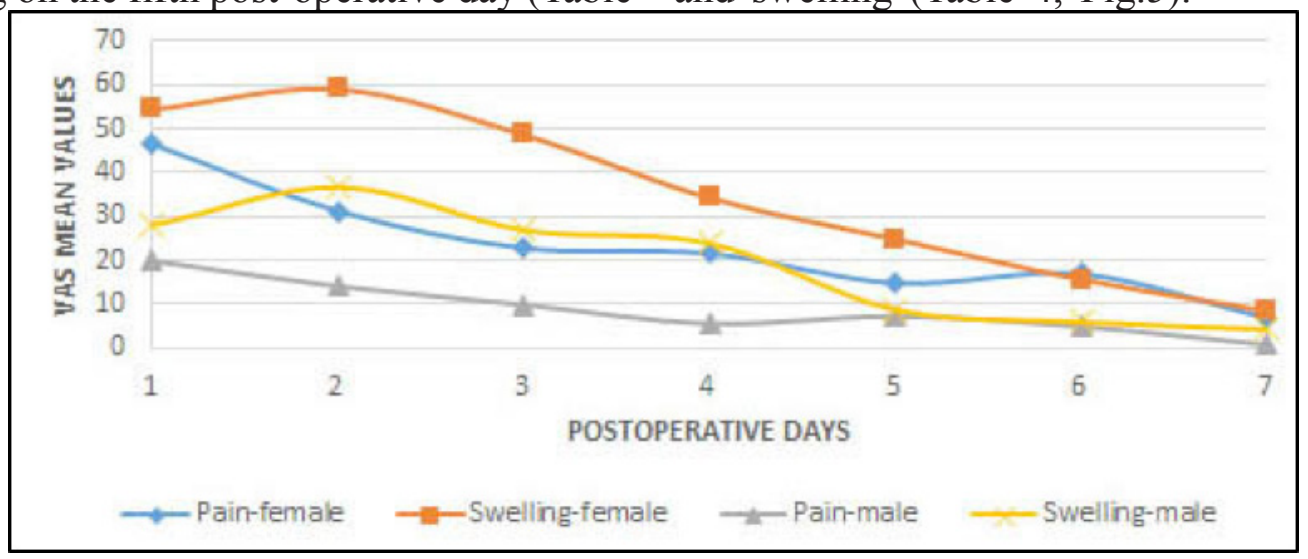

Fig.4: Gender-related postoperative pain and swelling values after PAS

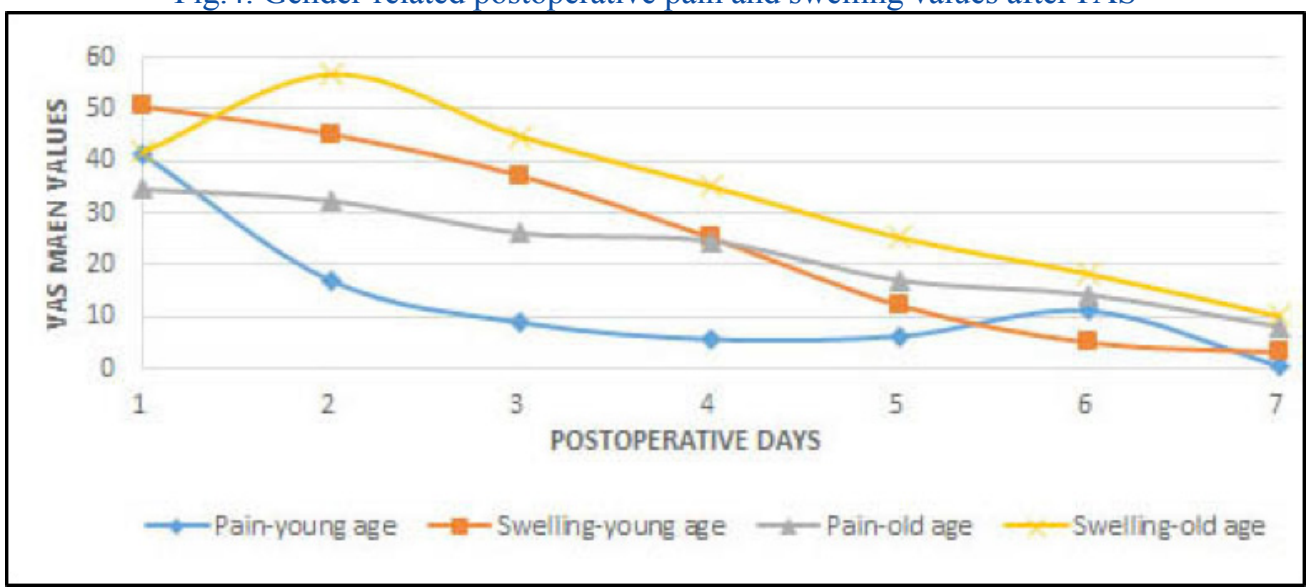

Fig.5: Age-related postoperative pain and swelling values after PAS

By comparing the mean post-operative pain and found that by grouping patients according to their age swelling values obtained for L3MS and PAS; the values show that in general L3MS caused, more pain and less swelling as compared to PAS, however, the or gender, there was no significant difference in the degree of pain or swelling within the tested groups. findings were statistically insignificant. . It was also (Table 6). 
Table (6): L3MS vs. PAS: Statistical significance* in age and gender concerning postoperative pain and swelling.

\section{Postoperative complain

Pain
Swelling \\ Swelling}

All patients
0.705
0.222

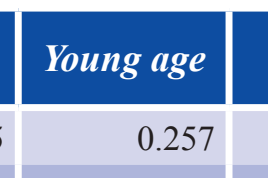

*Independent

\section{DISCUSSION}

The degree of pain and swelling are the main indicators of a patient's discomfort immediately after dental surgery ${ }^{(5)}$. In the present study, the VAS was used to asses pain and swelling, it is the most frequently used subjective method to measure these post-operative parameters ${ }^{(2,5)}$, also it is an effective and reliable tool ${ }^{(1,35)}$. However, it requires the patient to concentrate ${ }^{(36)}$ and be able to equate the length of the line with the amount of experienced pain or swelling ${ }^{(37)}$. For that reason, only patients aged 18 years or over were included in our study. In spite of that, some of our patients found it difficult to record the intensity of their pain or swelling using VAS.

The following cut points on the VAS have been considered: no pain $(0-4 \mathrm{~mm})$, mild pain $(5-44 \mathrm{~mm})$, moderate pain (45-74 mm), and severe pain (75- 100 $\mathrm{mm})^{(38)}$. Patients rated their experienced pain and swelling in this study for seven consecutive days, starting on the day of surgery to give detailed data related to the immediate post-operative discomfort, this was in conjunction with the work done by other researches ${ }^{(5,10,15,32)}$.

We obtained 76 complete and correct VAS readings for pain and swelling. Researchers found difficulty in securing patient collaboration when conducting clinical trials ${ }^{(16,19)}$. In the present study, $11.6 \%$ of the patients failed to use and/or complete the VAS for pain and swelling for the whole period of study.

L3MS: It involves trauma to the soft and hard tissues which results in inflammatory response in the form of various postoperative complications like pain and swelling ${ }^{(39)}$. Class III and/or level C type of LM3 impaction were excluded from the current study as these operations are more difficult and are associated with more post-operative discomfort ${ }^{(40-42)}$.

In our study, the maximum pain intensity recorded was on the day of surgery, which was in agreement with other studies ${ }^{(5,7,21)}$. Two patients (5\%) reported no pain on day 1 , and another remained pain free throughout the period of the study. This may be attributed to a high pain threshold or an under estimation of pain intensity. The distribution of patients' VAS scores for pain was skewed to the right: $25 \%$ of patients scored $0-46 ; 50 \%$ scored $0-54$; and
$75 \%$ scored $0-70$. The mean VAS score was 49 over 100 indicating that the pain intensity perceived by patients on day 1 after L3MS surgery is moderate. It was found that there was a good correlation between the present findings and previous studies with regards to pain intensity, where VAS scores of 4, 4.8, and 5 over 10 have been reported ${ }^{(4,8,9)}$.

Almost all patient reported swelling that reached a maximum on the first and second post-operative days; this was consistent with other studies $(5,8,10,11)$. On day 2, the mean VAS score of swelling was 32 over 100 , about $92.5 \%$ of patients suffered from mild to moderate swelling. One patient reported severe swelling (VAS score was100 over 100), an over estimation of swelling may be attributed to such an extreme value. In other studies, similar values of (36 over 100; and 2.6 over 10) have been reported ${ }^{(43,44)}$. This may indicate that the intensity of swelling perceived by patients after L3MS to be mild to moderate.

In accordance with other studies ${ }^{(22,23)}$, the age of patients had no influence on the immediate intensity of post $=$ operative pain and swelling. This may be due to the narrow range of patient ages that could mask the debilitating effect of age, as third molar extraction is mostly performed in young (45) and middleaged patients. Also, consistent with our findings, researchers found no correlation between gender and the intensity of post-operative pain and swelling ${ }^{(22,26)}$.

PAS: Post-operative pain and swelling may occur after PAS like any other surgical procedure. For the group that underwent PAS, only patients with one or two anterior teeth with periapical lesions were included in the study. This was to limit the anatomical variables, Researchers found that pain and swelling increased with the increase in the number of teeth treated ${ }^{(17,19)}$, also there was and more pain upon treating posterior teeth ${ }^{(18)}$.

In the present study, the maximum pain intensity was recorded on the day of surgery and the result was consistent with other studies ${ }^{(13,18,19)}$. Four patients $(11.1 \%)$ reported no pain on day 1 and throughout the period of the study. This may be attributed to the high pain threshold in those patients or it could be due to the under estimation of pain intensity. The distribution of patients' VAS scores for pain was skewed to the 
left: $25 \%$ of patients scored $0-10 ; 50 \%$ scored $0-30$; and $75 \%$ scored $0-62$. The mean VAS score was 37 over 100. From these results, we may conclude that as the pain intensity perceived by patients after PAS to be low to moderate. There is a good correlation between the present findings and previously reported studies where VAS scores were found to be 36,38 , and 39 over $100^{(18,19,46)}$.

Females reported a statistically significant increase in post-operative pain as compared to male patients. An explanation for this may be; that there was an over representation of females (66.7\%) in the group undergoing PAS. This figure was in agreement with Iqbal et al. (19). Many studies found no differences in pain intensity between the genders with regards to post-operative pain after periapical surgery ${ }^{(14,18,46)}$.Similarly It was found that age had no influence on post-operative pain ${ }^{(14,17,46)}$.

All our patients reported swelling that reached a maximum on the first post- operative day; this result was consistent with other studies ${ }^{(3,13,19)}$. On the contrary, other studies found the second postoperative day to be the time of maximum swelling $(15,17,32)$, this may be attributed to the administration of dexamethasone after the operation. On day 2, the mean VAS score was 51 over 100 and about $94.4 \%$ of the patients suffered from mild to moderate swelling. Similar values of 41 over 100; 46 over 100; and 4.7 over 10 were recorded by other studies ${ }^{(3,13,19)}$. This may indicate that the intensity of swelling perceived by patients after surgical endodontic treatment performed by the traditional techniques to be mild to moderate. We found that patient's age and gender had no influence on post-operative swelling. These finding were consistent with other studies ${ }^{(14,15,17,18,20)}$. CONCLUSION:

It could be concluded from our results that pain and swelling after L3MS and PAS peaked on days 1 and 2 respectively with mild to moderate intensity, then subsided gradually to minimal values on day 7 . The small sample size in this study may have made it difficult to draw a clear conclusion regarding the effect of patients' age and gender; therefore, further studies are recommended. Additionally careful consideration should to be given to other factors such as patient's fear and anxiety from dental procedures, oral hygiene and drug use.

\section{ACKNOWLEDGEMENT}

The author is gratefully thanks Dr. Fedwa AlSaffar for her assistance in language revision.

\section{CONFLICT OF INTEREST}

No potential conflict of interest relevant to this article was reported.

\section{REFERENCES}

1. Al-Samman AA, Al-Nuaime OS, Othman HA. Validity and Reliability of Full Cup Test in Pain Evaluation after Dental Surgery: A Comparison with Four Pain-Rating Scales in a Sample of Iraqi Patients. JODR 2016; 1:2-8.

2. Danda AK, Krishna Tatiparthi M, Narayanan V, Siddareddi A. Influence of primary and secondary closure of surgical wound after impacted mandibular third molar removal on postoperative pain and swelling. A comparative and split mouth study. J Oral Maxillofac Surg. 2010; 68:309-12.

3. Christiansen R, Kirkevang LL, Hørsted-Bindslev P, Wenzel A, Patient discomfort following periapical surgery. Oral Surg Oral Med Oral Pathol Oral Radiol Endod 2008;105:245-50.

4. Nageshwar N. Comma incision for impacted mandibular third molars. J Oral Maxillofac Surg 2002; 60:1506-9.

5. Pasqualini D, Cocero N, Castella A, Mela L, Bracco P. Primary and secondary closure of the surgical wound after removal of impacted mandibular third molars: A comparative study. Int J Oral Maxillofac Surg 2005;34:52-7.

6. Dolanmaz D, Esen A, Isik K, Candirli C. Effect of 2 flap designs on postoperative pain and swelling after impacted third molar surgery. Oral Surg Oral Med Oral Pathol Oral Radiol 2013;116: 244-6.

7. Sanchis-Bielsa JM, Hernández-Bazán S, Peñarrocha-Diago M. Flap repositioning versus conventional suturing in third molar surgery. Med Oral Patol Oral Cir Bucal 2008;13:E138-42.

8. Osunde OD, Adebola RA, Saheeb BD. A comparative study of the effect of suture-less and multiple suture techniques on inflammatory complications following third molar surgery. Int. J. Oral Maxillofac. Surg 2012;41: 1275-79.

9. Osunde OD, Saheeb BD, Adebola RA. Comparative study of effect of single and multiple suture techniques on inflammatory complications after third molar surgery. J Oral Maxillofac Surg 2011;69:971-76.

10. Bello SA, Olaitan AA, Ladeinde AL. A Randomized comparison of the effect of partial and total wound closure techniques on postoperative morbidity after mandibular third molar surgery. J Oral Maxillofac Surg 2011;69:e24-e30.

11. Hashemi HM, Beshkar M, Aghajani R. The effect of sutureless wound closure on postoperative pain and swelling after impacted mandibular third molar surgery. $\mathrm{Br}$ J Oral Maxillofac Surg 2012;50:256-8.

12. Ustun Y, Erdogan O, Esen E, Karsli E. Comparison of the effects of 2 doses of methylprednisolone on pain, swelling, and trismus after third molar surgery. Oral Surg Oral Med Oral Path Oral Radiol Endod 2003;96:535-9.

13. Kvist T, Reit C. Postoperative discomfort associated with surgical and nonsurgical endodontic retreatment. Endod Dent Traumatol. 2000;16:71-4.

14. Tsesis I, Fuss Z, Lin S, Tilinger G, Peled M. Analysis of postoperative symptoms following surgical endodontic treatment. Quintessence Int. 2003;34:756-60.

15. Tsesis I, Shoshani Y, Givol N, Yahalom R, Fuss Z, Taicher S. Comparison of quality of life after surgical endodontic treatment using two techniques: a prospective study. Oral Surg Oral Med Oral Pathol Oral Radiol Endod. 2005; 99:367-71.

16. Chong BS, Pitt Ford TR. Postoperative pain after root-end resection and filling. Oral Surg Oral Med Oral Pathol Oral Radiol Endod. 2005;100:762-6. 
17. Penarrocha M, Garcia B, Marti E, Balaguer J. Pain and inflammation after periapical surgery in 60 patients. J Oral Maxillofac Surg. 2006;64:429-33.

18. Lin S, Levin L, Emodi O, Abu El-Naaj I, Peled M. Etodolac versus dexamethasone effect in reduction of postoperative symptoms following surgical endodontic treatment: a double-blind study. Oral Surg Oral Med Oral Pathol Oral Radiol Endod. 2006;101:814-7.

19. Iqbal MK, Kratchman SI, Guess GM, Karabucak B, Kim S. Microscopic periradicular surgery: perioperative predictors for postoperative clinical outcomes and quality of life assessment. J Endod. 2007;33:239-44.

20. García B, Penarrocha M, Martí E, Gay-Escodad C, Von Arx T. Pain and swelling after periapical surgery related to oral hygiene and smoking. Oral Surg Oral Med Oral Pathol Oral Radiol Endod. 2007;104:271-6.

21. Kareem JJ. A Comparison between primary and secondary wound closure after surgical removal of lower third molars according to pain and swelling. MDJ 2008; 5: 410-417.

22. Baqain ZH, Karaky AA, Sawair F, Khraisat A, Duaibis $\mathrm{R}$, Rajab LD.Frequency estimates and risk factors for postoperative morbidity after third molar removal: a prospective cohort study. J Oral Maxillofac Surg. 2008;66:2276-83.

23. Bui CH, Seldin EB, Dodson TB. Types, frequencies, and risk factors for complications after third molar extraction. $\mathrm{J}$ Oral Maxillofac Surg. 2003;61:1379-89.

24. Adeyemo WL, Ogunlewe MO, Ladeinde AL, Hassan OO, Taiwo OA. A comparative study of surgical morbidity associated with mandibular third-molar surgery in young and aging populations. J Contemp Dent Pract 2010;11:E001-8.

25. de Santana-Santos T, de Souza-Santos JAS, Martins-Filho PRS, da Silva LCF, de Oliveira e Silva ED, Gomes ACA. Prediction of postoperative facial swelling, pain and trismus following third molar surgery based on preoperative variables. Med Oral Patol Oral Cir Bucal. 2013;18:e65-70.

26. Akadiri OA, Okoje VN, Arotiba JT. Identification of risk factors for short-term morbidity in third molar surgery. Odontostomatol Trop 2008;31:5-10.

27. Bienstock DA, Dodson TB, Perrott DH, Chuang SK Prognostic factors affecting the duration of disability after third molar removal. J Oral Maxillofac Surg 2011;69:12727.

28. Gaya MVO, Capilla MV, Mateos RG. Relation of patient and surgical variables to postoperative pain and inflammation in the extraction of third molars. Medicinal Oral 2002;7:360369.

29. Kim JC, Choi SS, Wang SJ, Kim SG. Minor complications after mandibular third molar surgery: type, incidence, and possible prevention. Oral Surg Oral Med Oral Pathol Oral Radiol Endod. 2006;102:e4-11.

30. Benediktsdóttir IS, Wenzel A, Petersen JK, Hintze H. Mandibular third molar removal: risk indicators for extended operation time, postoperative pain, and complications. Oral Surg Oral Med Oral Pathol Oral Radiol Endod 2004;97:438-46.

31. Capuzzi P, Montebugnoli L, Vaccaro MA. Extraction of im $\neg$ pacted third molars. A longitudinal prospective study on factors that affect postoperative recovery. Oral Surg Oral Med Oral Pathol. 1994;77:341-3.
32. Peñarrocha-Diago $M$, Maestre-Ferrín L, PeñarrochaOltra D, Gay-Escoda C, von-Arx T, Peñarrocha-Diago M. Pain and swelling after periapical surgery related to the hemostatic agent used: Anesthetic solution with vasoconstrictor or aluminum chloride. Med Oral Patol Oral Cir Bucal. 2012;17:e594-600.

33. Payer M, Jakse N, Pertl C, Truschnegg A, Lechner E, Eskici A. The clinical effect of LLLT in endodontic surgery: a prospective study on 72 cases. Oral Surg Oral Med Oral Pathol Oral Radiol Endod. 2005;100:375-9.

34. Kreisler MB, Haj HA, Noroozi N, Willershausen B. Efficacy of low level laser therapy in reducing postoperative pain after endodontic surgery: a randomized double blind clinical study. Int J Oral Maxillofac Surg. 2004;33:38-41.

35. Berge TI: The visual analogue scale in observer assessment of postoperative swelling subsequent to third molar surgery. Acta Odontol Scand 1989;47:167-74.

36. Briggs M, Closs JS. A descriptive study of the use of visual analogue scales and verbal rating scales for the assessment of postoperative pain in orthopedic patients. J Pain Symptom Manage 1999;18:438-46.

37. Cook AK, Niven CA, Downs MG. Assessing the pain of people with cognitive impairment. Int J Geriatr Psychiatry 1999; 14: 421-5.

38. Jensen MP, Chen C, Brugger AM. Interpretation of visual analog scale ratings and change scores: a reanalysis of two clinical trials of postoperative pain. J Pain 2003; 4: 407-14.

39. Lopes V, Mumenya R, Feinmann C, Harris, M. Third molar surgery: an audit of the indications for surgery, postoperative complaints and patient satisfaction. Br J Oral Maxillofac Surg 1995;33: 33-5.

40. Oikarinen K. Postoperative pain after mandibular thirdmolar surgery. Acta Odontol Scand 1991;49:7-13.

41. Garcia Garcia A, Gude Sampedro F, Gandara Rey J, Gallas Torreira M. Trismus and pain after removal of impacted lower third molars. J Oral Maxillofac Surg 1997;55:1223-6.

42. Yuasa H, Sugiura M. Clinical postoperative findings after removal of impacted mandibular third molars: prediction of postoperative facial swelling and pain based on preoperative variables. Br J Oral Maxillofac Surg 2004;42:209-14.

43. Koyuncu BÖ, Zeytinoğlu M, Çetingül E. Comparison of 2 different flap techniques in the surgical removal of bilateral impacted mandibular third molars. Turk J Med Sci 2013;43:891-98.

44. Chaudhary M, Singh M, Singh S, Singh S P, and Kaur G.Primary and secondary closure technique following removal of impacted mandibular third molars: A comparative study. Natl J Maxillofac Surg. 2012; 3:10-4.

45. Grossi GB, Maiorana C, Garramone RA, Borgonovo A, Creminelli L, Santoro F. Assessing postoperative discomfort after third molar surgery: a prospective study. J Oral Maxillofac Surg 2007;65:901-17.

46. Seymour RA, Meechan JG, Blair GS. Postoperative pain after apicectomy. A clinical investigation. Int Endod 1986;19:242-7. 